\title{
Analysis of a three-phase AC chopper with high power factor for the use in "PV-to-Heat" applications
}

\author{
Manuel Raeber IEEE Member, Andreas Heinzelmann, Jimmy Oliapuram \\ Institute for Energy Systems and Fluid Engineering (IEFE) \\ ZHAW Zurich University of Applied Sciences \\ 8400 Winterthur, Switzerland
}

\begin{abstract}
The decreasing cost of photovoltaic (PV) systems allows the production of cheap renewable electricity. This has led to an increasing number of installed systems during the past years. Since the storage of electrical energy is still rather expensive, the optimization of the self-consumption coverage gains importance. One solution to higher self-consumption is a method called "PVto-Heat", where excess PV energy is not fed into the grid but stored in the form of hot water in the domestic boiler. This article describes a simplified hardware approach for a three-phase PWM chopper for AC/AC conversion. It is suited for low inductive loads like electric heaters. Compared to existing systems, the proposed converter design offers equal or better performance at very low cost and small size. The circuit allows full control of the power flow and provides sinusoidal and symmetrical load currents. The average electrical efficiency is $94.7 \%$ for a $6 \mathrm{~kW}$ test system. Unlike certain commercial products, there is no need to use a custom heater or access the star point of the load resistor.
\end{abstract}

Keywords - Power-to-Heat, PV-to-Heat, Three-phase chopper, Self-consumption optimization

\section{INTRODUCTION}

"PV-to-Heat" is a method to increase the self-consumption in a household without the need of an additional battery electrical storage system (BESS). Excess PV energy is not fed back to the grid but used to produce hot water and stored in the domestic boiler. Direct systems work with an electric heating element, whereas indirect systems use a heat pump to produce hot water (see [1], [2] and [3]). The overall efficiency of indirect systems is higher due to the coefficient of performance (COP) of the heat pump being higher than 1. However, for low-power applications, direct systems are an interesting option as the existing installation can be upgraded with only few additional components. Usually, different types of power electronic converters are considered for direct PV-to-heat applications. They can adjust the power level of the heating element within milliseconds and hence are well suited to follow the highly volatile PV generation curve.

Fig. 1 shows the main components of a three-phase "PV-toHeat" installation: PV energy is fed into the AC lines through a PV inverter. The energy manager includes a two-way energy meter which measures the power flow from/to the grid and sets the power level of the "PV-to-Heat" device to maximize the self-consumption coverage of the household.

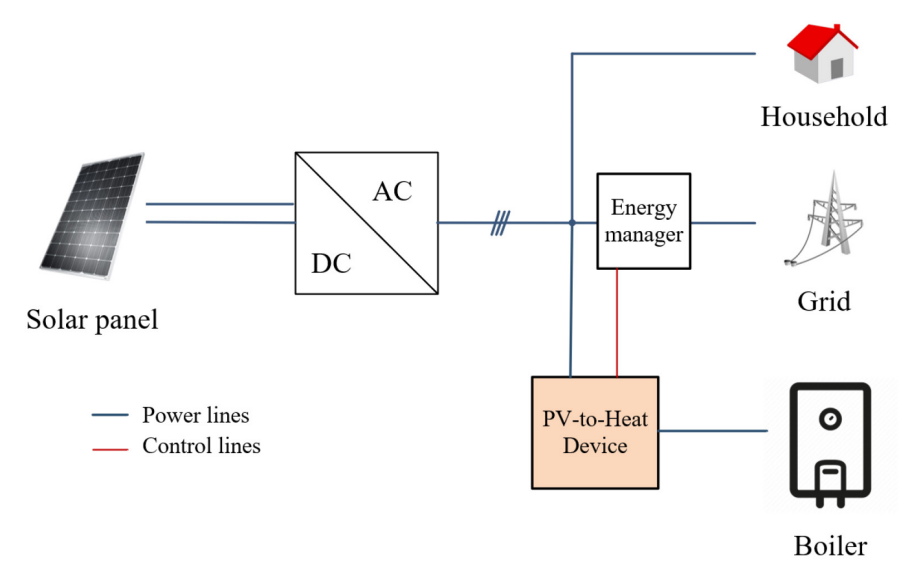

FIG. 1. OVERVIEW OF A THREE-PHASE "PV-TO-HEAT" SYSTEM

This paper proposes the use of a simple AC chopper circuit for the power control of a hot-water boiler to optimize the selfconsumption coverage of a household with a PV installation. On the following pages the functionality and the achieved performance of the method is presented. Section II summarizes relevant publications and commercially available products. In Section III, the method is described in detail. The hardware prototype is shown in Section IV and Section $\mathrm{V}$ presents the measurement results and compares them to the simulation.

\section{STATE OF THE ART AND MARKET STUDY}

Three-phase AC choppers have been proposed in the past for controlling a single resistive load ([4]), three independent inductive loads ([5]) and electric motors ([6]). In this application area they compete with other three-phase rectifier and inverter topologies. In Table 1, the most promising methods for direct "Power-to-Heat" are listed. The only options that deliver a stepless output power with high power factor (PF) and symmetrical phase currents are the standard variable-frequency drive technology ([7]) and the conventional buck-boost AC-AC converter ([8]). However, the cost and losses of such devices are rather high. Current-source inverters and matrix converters are not considered due to their limited relevance in the power range below $10 \mathrm{~kW}$. 
TABLE 1: OVERVIEW OF “PV-TO-HEAT" METHODS

\begin{tabular}{|c|c|}
\hline Architecture & Description \\
\hline 1-phase PWM [9] & $\begin{array}{l}\text { Only } 1 \text { phase is controlled, the } 2 \\
\text { others are only turned ON or OFF } \\
\text { (+) Stepless output power } \\
\text { (-) Asymmetrical phase currents } \\
\text { (-) Requires neutral conductor }\end{array}$ \\
\hline $\begin{array}{l}\text { Phase-fired controller } \\
\text { (SCR) }[10]\end{array}$ & $\begin{array}{l}\text { Thyristor converter } \\
(-) \text { Low power factor }\end{array}$ \\
\hline Relay control & $\begin{array}{l}2 \text { operation modes: ON or OFF } \\
\text { (-) No power control }\end{array}$ \\
\hline $\begin{array}{l}\text { 3-phase half-bridge PWM } \\
\text { inverter with DC-link [7] }\end{array}$ & $\begin{array}{l}\text { Standard freq. converter topology } \\
(+) \text { Stepless output power, high THD }\end{array}$ \\
\hline $\begin{array}{l}\text { Three-phase buck-boost } \\
\text { AC-AC converter [8] }\end{array}$ & $\begin{array}{l}\text { (+) Buck and boost operation } \\
(-) \text { Only resistive loads }\end{array}$ \\
\hline Individual phase relays & $\begin{array}{l}\text { (-) Only } 3 \text { power levels } \\
\text { (-) Asymmetrical phase currents } \\
\text { (-) Requires neutral conductor }\end{array}$ \\
\hline Switchable load resistor & $\begin{array}{l}\text { Resistor with several power levels } \\
\text { (-) HW effort for relays and resistors }\end{array}$ \\
\hline
\end{tabular}

The demand for variable-power water heaters has led to many commercial products. Table 2 shows an overview of the market research. The working principle of the devices is not published in detail and most devices are designed to work only with their own power manager hardware and/or custom electric heater. The usual power rating ranges from 3 to $9 \mathrm{~kW}$, with many products offering around $6 \mathrm{~kW}$.

TABLE 2: OVERVIEW OF COMMERCIAL "PV-TO-HEAT" DEVICES

\begin{tabular}{|c|c|c|c|c|}
\hline Manufacturer & Type & Specs & $\eta$ & $\begin{array}{l}\text { Retail price } \\
(€ / \mathbf{k W})\end{array}$ \\
\hline Smartfox & Booster & $3 \mathrm{~kW}, 1$ phase & $>0.99$ & $\mathrm{Q} 4 / 19$ \\
\hline Smartfox & $\begin{array}{l}\text { Thyristor- } \\
\text { steller } 102787\end{array}$ & $6 \mathrm{~kW}$ & $\mathrm{n} / \mathrm{a}$ & $57 .-$ \\
\hline Fronius & Ohmpilot & $9 \mathrm{~kW}$ & $\mathrm{n} / \mathrm{a}$ & 81.- \\
\hline Resol & $\begin{array}{l}\text { DeltaTherm } \\
\text { PV }\end{array}$ & $3 \mathrm{~kW}, 1$ phase & $\mathrm{n} / \mathrm{a}$ & 333.- \\
\hline SENEC & Heat-Box & $6 \mathrm{~kW}$ & $\mathrm{n} / \mathrm{a}$ & 127.- \\
\hline Juratherm & Reparco & $\begin{array}{l}6 \mathrm{~kW}, 31 \\
\text { Power levels }\end{array}$ & $\mathrm{n} / \mathrm{a}$ & $383 .-1$ \\
\hline $\mathrm{EGO}$ & $\begin{array}{l}\text { Smart } \\
\text { Heater }\end{array}$ & $\begin{array}{l}3.5 \mathrm{~kW}, 7 \\
\text { Power levels }\end{array}$ & $\mathrm{n} / \mathrm{a}$ & 214.- \\
\hline $\begin{array}{l}\text { Siemens, } \\
\text { ABB, } \\
\text { Schneider, } \\
\text { Danfoss etc. }\end{array}$ & $\begin{array}{l}\text { Industrial } \\
\text { three-phase } \\
\text { frequency } \\
\text { inverter }\end{array}$ & $1 \ldots 11 \mathrm{~kW}$ & $\sim 0.95$ & $>133 . .^{2}$ \\
\hline
\end{tabular}

\section{DESCRIPTION OF THE PROPOSED CIRCUIT}

The proposed circuit consists of three single IGBTs or MOSFETs with integrated free-wheeling diode. IGBTs are cheaper but MOSFETs offer better reverse conducting mode and lower switching losses. Fig. 2 shows the simplified diagram of the AC chopper realized with IGBT devices. R, S and T are the phases of a $50 / 60 \mathrm{~Hz} 400 \mathrm{~V}$ grid.

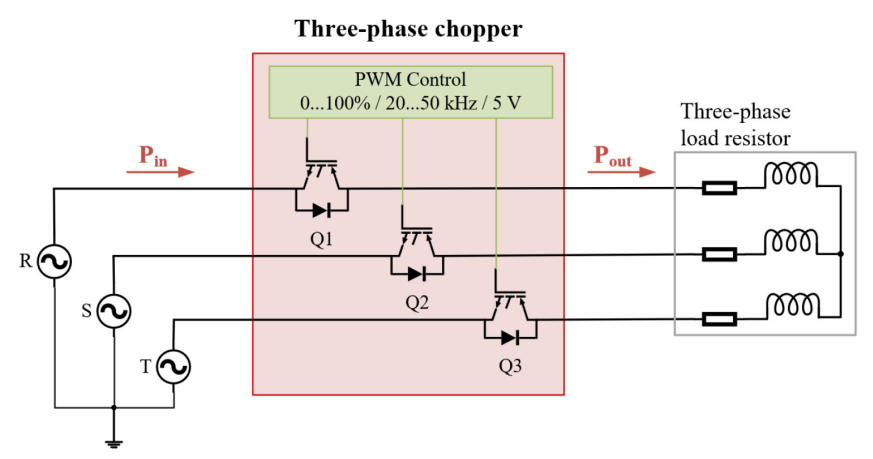

FIG. 2. SIMPLIFIED CIRCUIT DIAGRAM OF THREE-PHASE PWM CHOPPER

All three switches can be controlled by an identical PWM signal. When one of the switches is turned on, a current builds up according to the voltage difference of the phases as given in (1) to (3). The phase currents are shared as a function of the sinusoidal phase voltages and therefore show a sinusoidal waveform as well.

$$
\begin{aligned}
& i_{Q 1}=\frac{2 u_{R}-u_{S}-u_{T}}{2 R_{L}} \\
& i_{Q 2}=\frac{2 u_{S}-u_{R}-u_{T}}{2 R_{L}} \\
& i_{Q 3}=\frac{2 u_{T}-u_{R}-u_{U}}{2 R_{L}}
\end{aligned}
$$

The load current is pulsed at the switching frequency. An LC input filter is used to improve the grid current quality and reduce the high frequency harmonics. For a symmetrical threephase grid, the phase current $I_{\text {in }}$ and total power $P_{\text {in }}$ are calculated in (4) without consideration of losses.

$$
I_{\text {in }}=\frac{D \cdot U_{i n}}{R_{L}}, \quad P_{i n}=3 \cdot \frac{D \cdot U_{i n}{ }^{2}}{R_{L}}
$$

Due to the parasitic inductance of the load resistor and the connecting cables, a snubber circuit must be foreseen to protect the semiconductor switches. There is no freewheeling path for the load current in the proposed design. A possible implementation with an RC-snubber is shown in Fig. 3.

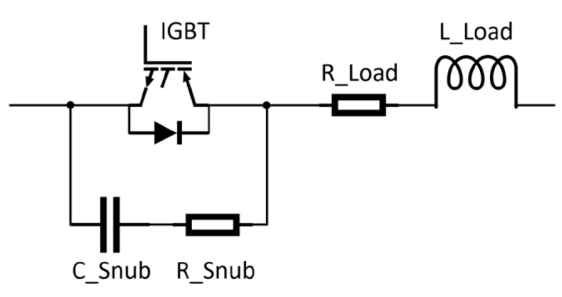

Fig. 3. DEtaILED EQUivalent CIRCUIT DIAGRAM OF ONE PHASE WITH RC SNUBBER AND LOAD IMPEDANCE 


\section{HARDWARE PROTOTYPE}

A hardware prototype with a power rating of $6 \mathrm{~kW}$ was built to verify the simulation results. The output power can be controlled stepless from 0 to $6 \mathrm{~kW}$. Table 3 lists the components of the prototype. The individual hardware cost for an IGBT based design is around $40 €$ at 1000 pieces. As a load, electric heaters were used with a total power of $6 \mathrm{~kW}$.

TABLE 3: BILL OF MATERIAL

\begin{tabular}{|c|c|c|c|c|}
\hline Component & $\overline{~ L a b e l ~}$ & Value / Type & Pcs & $\begin{array}{l}\begin{array}{l}\text { Cost } \\
(€)\end{array} \\
\text { (E) }\end{array}$ \\
\hline Filter capacitor & $\mathrm{C}_{\mathrm{F}}$ & $2.2 \mathrm{uF}$ & 3 & 2.- \\
\hline Filter inductor & $\mathrm{L}_{\mathrm{F}}$ & $3 \times 5 \mathrm{mH} \mathrm{CM}$ & 1 & $5 .-$ \\
\hline Snubber capacitor & $\mathrm{Cs}_{\mathrm{s}}$ & $2.2 \mathrm{nF}$ & 6 & 1.20 \\
\hline Snubber resistor & $\mathrm{R}_{\mathrm{S}}$ & $47 \mathrm{Ohm} / 5 \mathrm{~W}$ & 3 & 1.20 \\
\hline $\begin{array}{l}\text { MOSFET or } \\
\text { IGBT }\end{array}$ & Q1...Q3 & $\begin{array}{l}\text { 3CM090065 or } \\
\text { IHW30N120R5 }\end{array}$ & 3 & $\begin{array}{l}30 .- \\
10 .-\end{array}$ \\
\hline $\begin{array}{l}\text { Isolated } \\
\text { Gatedriver }\end{array}$ & - & $\begin{array}{l}1 \mathrm{~W} \text { DC/DC \& } \\
2 \mathrm{~A} \text { Optocoupler }\end{array}$ & 3 & 10.80 \\
\hline Heat sink & - & SK $48150 \mathrm{~mm}$ & 1 & $2 .-$ \\
\hline $\mathrm{PCB}$ & - & $70 \mu \mathrm{m}, 2$-layer & 1 & $3 .-$ \\
\hline Case & - & Tbd & 1 & $5 .-$ \\
\hline Load & $\mathrm{R}_{\mathrm{L}}$ & Kettle $3 \mathrm{x} \sim 2 \mathrm{~kW}$ & - & - \\
\hline
\end{tabular}

Fig. 4 shows the hardware prototype equipped with the components specified in Table 3. The SiC MOSFETs are mounted on an isolated heat sink. They are driven with $15 \mathrm{~V}$ and controlled via a common PWM input. With the identical hardware setup, any standard MOSFET or IGBT could be used instead of the $\mathrm{SiC}$ devices. The snubber resistors have a thermal power capability of $5 \mathrm{~W}$.

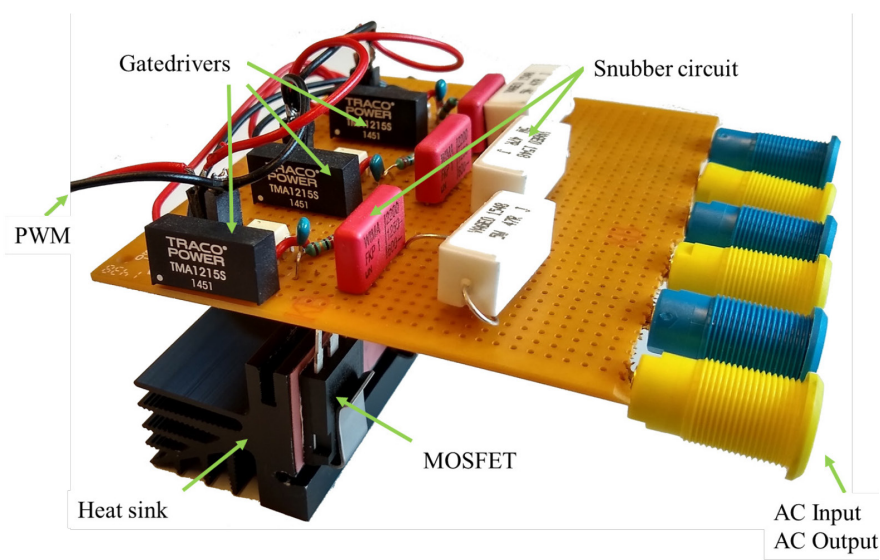

Fig. 4. HARDWARE PROTOTYPE WITH SiC MOSFETS

\section{RESUlts}

This chapter presents the simulation and measurement results. Where applicable, the same component values were used for simulation and hardware prototype.

\section{A. Simulation settings}

The electric simulation was performed using the software tool PLECS. Care was taken to use realistic values for the simulation parameters given in Table 4.

TABLE 4: COMPONENT VALUES AND SETTINGS USED IN THE SIMULATION

\begin{tabular}{lll}
\hline \hline Parameter & Symbol & Value \\
\hline Filter capacitance & $C_{F}$ & $2.2 \mathrm{uF}$ \\
Filter inductance & $L_{F}$ & $100 \mathrm{uH}$ \\
Filter resistance & $R_{F}$ & $100 \mathrm{~m} \Omega$ \\
Snubber capacitance & $C_{S}$ & $2.2 \mathrm{nF}$ \\
Snubber resistance & $R_{S}$ & $47 \Omega$ \\
Load inductance & $L_{L}$ & $5 \mathrm{uH}$ \\
Load resistance & $R_{L}$ & $\sim 28 \Omega$ \\
Duty-cycle of PWM & $D$ & 0.7 \\
Switching frequency & $f_{S}$ & $20 \mathrm{kHz}$ \\
\hline \hline
\end{tabular}

\section{B. Snubber circuit dimensioning}

The snubber circuit is optimized by using the same PLECS electric simulation model as for the main simulations defined in Table 4. The losses in the snubber circuit depend on the parameter $R_{S}$ and $C_{S}$. In the simulation, $U_{C E}$ (or $U_{D S}$ for MOSFETs) must be below $726 \mathrm{~V}$ to allow the use of $900 \mathrm{~V}$ semiconductors (with $100 \mathrm{~V}$ voltage reserve in a $440 \mathrm{~V}$ grid). Therefore, the snubber capacitance $C_{S}$ must be over $2 \mathrm{nF}$ for $L_{L}$ of $5 \mathrm{uH}$. Fig. 5 shows the snubber losses as a function of the snubber parameter.

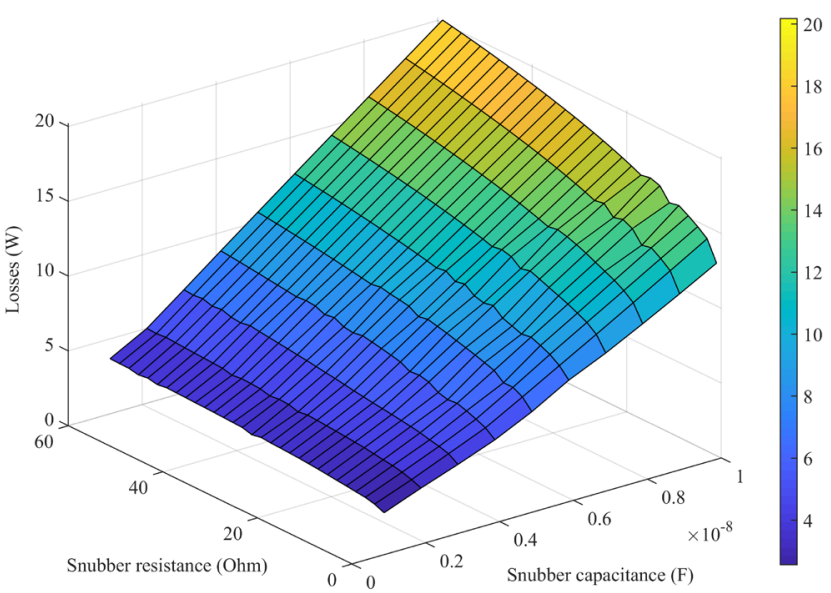

Fig. 5. SimUlation OF SNUBBER LOSSES AS A FUNCTION OF SNUBBER R AND C VALUES

For a higher nominal power output of the converter, the snubber capacitance must be increased accordingly to fulfill the same overvoltage limit of $900 \mathrm{~V}$.

\section{Converter efficiency and power factor}

The overall converter efficiency is calculated according to (5). $P_{\text {in }}$ and $P_{\text {out }}$ are defined in Fig. 2. Conduction losses $P_{C}$ and switching losses $P_{S w}$ of the MOSFETs/IGBTs, gate drive supply 
$P_{Q}$, snubber losses $P_{S n}$, ohmic losses $P_{R}$ of the wiring and filter losses $P_{\text {Filt }}$ are considered as shown in (6).

$$
\begin{gathered}
\eta=\frac{P_{\text {out }}}{P_{\text {in }}} \\
P_{V}=3 \cdot\left(P_{C}+P_{S w}+P_{Q}+P_{S n}+P_{R}+P_{\text {Filt }}\right)
\end{gathered}
$$

For the given operating conditions $\left(U_{\text {in }}=230 \mathrm{~V}, D=0.7\right.$, $\left.P_{n}=6 \mathrm{~kW}\right)$, the total losses are calculated with the estimated values in (7) and add up to $135 \mathrm{~W}$. The snubber losses are constant over the duty-cycle but linearly increasing with the switching frequency.

$$
P_{V}=3 \cdot(5+3+1+15+17+12)=135 \mathrm{~W}
$$

\section{Simulation results}

Fig. 6 shows the simulated input voltage and current at $70 \%$ duty-cycle for a nominal load of $6 \mathrm{~kW}$. The analyzed simulation parameters are determined using the PLECS analysis functions and listed in Table 6.
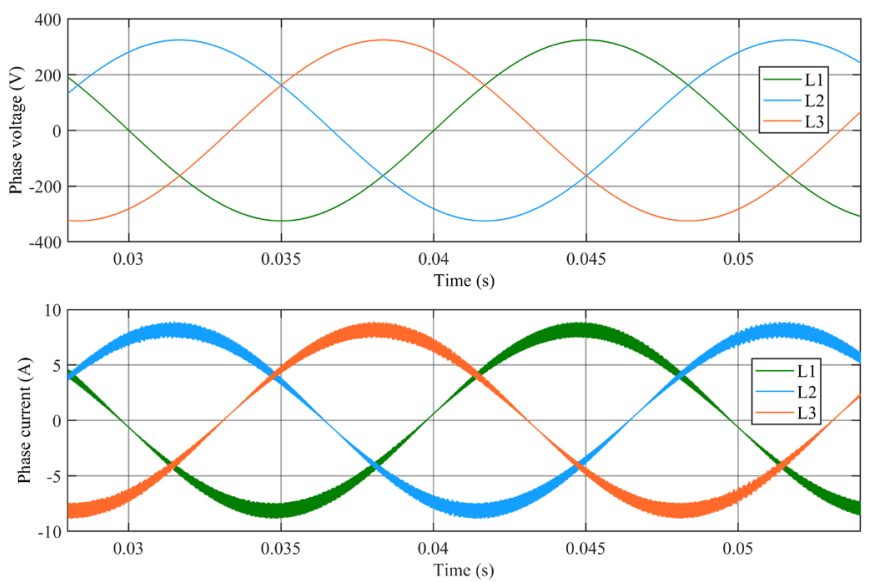

Fig. 6. SiMULATION OF INPUT CURRENT AT $50 \mathrm{~Hz} 3$ X400 V AND 70\% PWM

\section{E. Measurements}

Input voltage, output voltage and current of the prototype were measured to determine the conversion efficiency and power factor. The measurement can be compared directly to the simulation output. The measuring instruments used are listed in Table 5.

TABLE 5: MEASUREMENT EQUIPMENT

\begin{tabular}{lll}
\hline \hline Device & Manufacturer & Type \\
\hline Oscilloscope & Lecroy & HDO4034A \\
Current meter & Lecroy & CP030 \\
Voltage meter & Lecroy & HVD3106 \\
Power analyzer & Infratek & 108A \\
PWM Generator & Tektronix & AFG2021 \\
\hline \hline
\end{tabular}

In Fig. 7 the input voltage and current of the prototype running at the simulated operating conditions is shown. The prototype was connected to the grid by means of a three-phase filter specified in Table 4. Input power and current, efficiency, power factor (PF) and the total harmonic distortion (THD) of the input current are measured directly by the power analyzer. These values are given in Table 6 and compared to the simulation output.
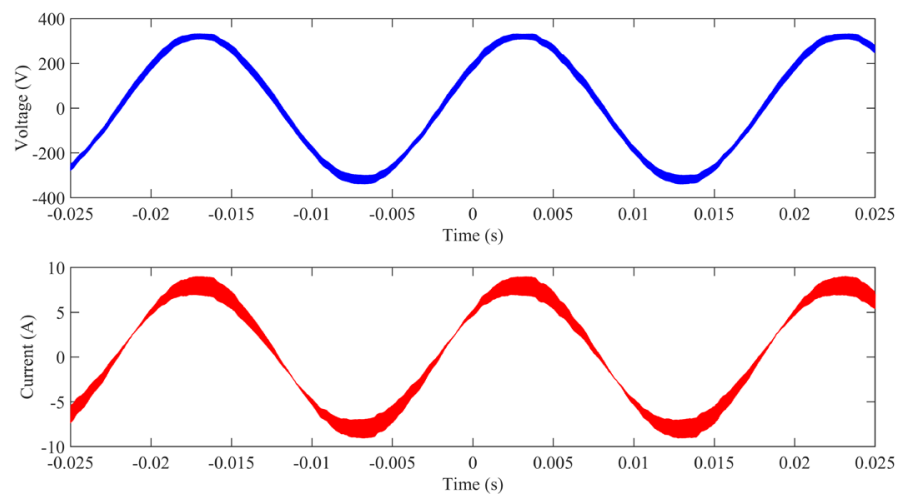

Fig. 7. MEASUREMENT OF PROTOTYPE INPUT VOLTAGE (TOP, BLUE) AND PHASE CURRENT (BOTTOM, RED)

TABLE 6: MEASUREMENT RESULTS AT $230 \mathrm{~V} / 70 \%$ / $20 \mathrm{KHZ}$ AND COMPARISON WITH SIMULATION OUTPUT

\begin{tabular}{lll}
\hline \hline Parameter & Simulation & Measurement \\
\hline Input power $P_{\text {in }}$ & $3968 \mathrm{~W}$ & $3960 \mathrm{~W}$ \\
Input current $I_{\text {in }}$ & $5.78 \mathrm{~A}$ & $5.64 \mathrm{~A}$ \\
Power factor $P F$ & - & 0.991 \\
$T H D_{i}(<100 \mathrm{kHz})$ & $5.9 \%$ & $9 \%$ \\
$\cos (\varphi)_{I}(50 \mathrm{~Hz})$ & 0.98 & 0.99 \\
$U_{C E} \max$ & $581 \mathrm{~V}$ & $603 \mathrm{~V}$ \\
Efficiency $\eta$ & $96.6 \%$ & $95.5 \%$ \\
\hline \hline
\end{tabular}

\section{CONCLUSION}

This paper suggests the use of a three-phase AC chopper for "PV-to-Heat" applications as a cost-effective method to increase the self-consumption coverage of households with a PV installation. A comparison of the electrical system simulation and the hardware test measurements confirms the sinusoidal grid currents and low harmonic distortion of the new method. The measured efficiency value is $1.1 \%$ below the calculated one. Reasons for this are suspected in the neglected losses due to the skin effect in the cables and core losses in the input inductors and $\mathrm{CM}$ choke. Furthermore, power measurements with the Infratek $108 \mathrm{~A}$ at $20 \mathrm{kHz}$ are subject to a reduced accuracy of above $1 \%$. The measured efficiency of the hardware prototype including filter losses is $94.7 \%$ over the range of 20 to $90 \%$ duty-cycle. Unlike some commercial solutions, the presented method offers symmetrical load currents and a high power factor. Simulations show that a higher nominal power rating of e.g. $12 \mathrm{~kW}$ is possible with the same technical approach resulting in approximately twice the 
snubber losses.

It is known to the authors that there are more efficient ways for "PV-to-Heat" like the use of heat pumps. However, for households with a moderate demand of hot water, the proposed circuit seems a reasonable approach especially for its low-cost BoM of $40 €$. The price of commercial products which have similar specifications start at around $750 €$. Besides "PV-toHeat" the presented circuit might be used for other lowinductive applications such as hot-air dryers, programmable AC loads or controllable heaters in process engineering.

\section{REFERENCES}

[1] E. Psimopoulos, E. Bee, R. Luthander, and C. Bales, "Smart Control Strategy for PV and Heat Pump System Utilizing Thermal and Electrical Storage and Forecast Services," in Proceedings of SWC2017/SHC2017, Abu Dhabi, 2017, pp. 1-12.

[2] F. P. Baumgartner et al., "THE SWISS PV WALL SYSTEM TO MAXIMISE SELF-CONSUMPTION IN A SINGLE BUILDING ELEMENT," presented at the 30th European Photovoltaic Solar Energy Conference and Exhibition, Hamburg, 2015.

[3] C. J. C. Williams, J. O. Binder, and T. Kelm, "Demand side management through heat pumps, thermal storage and battery storage to increase local self-consumption and grid compatibility of PV systems," in 2012 3rd IEEE PES Innovative Smart Grid Technologies Europe (ISGT Europe), Berlin, Germany, 2012, pp. 1-6.

[4] O. Ursaru, M. Lucanu, C. Aghion, and L. Tigaeru, "THREE-PHASE AC CHOPPER WITH IGBT's," presented at the International Conference on DEVELOPMENT AND APPLICATION SYSTEMS, Suceava, Romania, 2004.

[5] S. Fujikura, A. Ueda, A. Torii, and N. Kobayashi, "Analysis of a ThreePhase Buck-Boost AC Chopper Controlled in Two Phases," in 2007 Power Conversion Conference - Nagoya, Nagoya, Japan, 2007, pp. 824-830.

[6] J. Thankachan and S. George, "A novel switching scheme for Three phase PWM AC Chopper fed induction motor," in 2012 IEEE 5th India International Conference on Power Electronics (IICPE), Delhi, India, 2012, pp. 1-4.

[7] J. W. Kolar, T. Friedli, J. Rodriguez, and P. W. Wheeler, "Review of Three-Phase PWM AC-AC Converter Topologies," IEEE Trans. Ind. Electron., vol. 58, no. 11, pp. 4988-5006, Nov. 2011.

[8] A. A. Khan and H. Cha, "A novel highly reliable three-phase buckboost ac-ac converter," in 2016 IEEE Energy Conversion Congress and Exposition (ECCE), Milwaukee, WI, USA, 2016, pp. 1-7.

[9] S. M. Bashi, N. F. Mailah, and W. B. Cheng, "Development of a SinglePhase PWM AC Controller," Pertanika J Sci Technol, vol. 16, p. 10 , 2008.

[10] R. Stevanovi, "A Thyristor Full-Wave Rectifier With Full Control of the Conducting Angle," ELECTRONICS, vol. 13, no. 1, p. 5, 2009. 